This item was submitted to Loughborough's Research Repository by the author.

Items in Figshare are protected by copyright, with all rights reserved, unless otherwise indicated.

\title{
Uncertainty in Photovoltaic performance parameters - dependence on location and material
}

PLEASE CITE THE PUBLISHED VERSION

PUBLISHER

PVSEC / Elsevier

VERSION

NA (Not Applicable or Unknown)

LICENCE

CC BY-NC-ND 4.0

\section{REPOSITORY RECORD}

Strobel, Matthias, Ralph Gottschalg, Gabi Friesen, and Hans G. Beyer. 2019. "Uncertainty in Photovoltaic Performance Parameters - Dependence on Location and Material”. figshare. https://hdl.handle.net/2134/5080. 
This item was submitted to Loughborough's Institutional Repository (https://dspace.lboro.ac.uk/) by the author and is made available under the following Creative Commons Licence conditions.

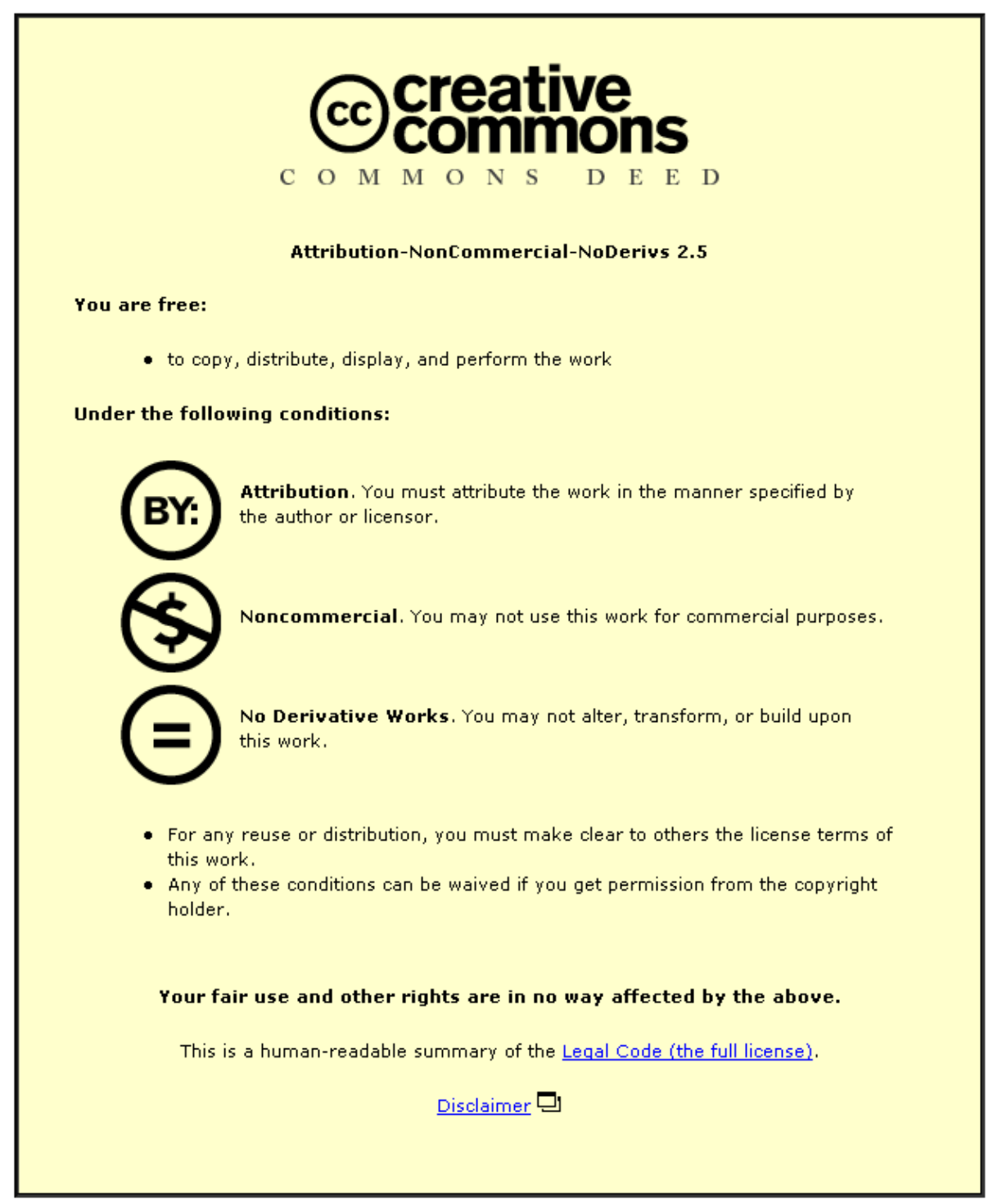

For the full text of this licence, please go to: http://creativecommons.org/licenses/by-nc-nd/2.5/ 


\title{
UNCERTAINTY IN PHOTOVOLTAIC PERFORMANCE PARAMETERS - DEPENDENCE ON LOCATION AND MATERIAL
}

\author{
M. B. Strobel ${ }^{1}$, R. Gottschalg ${ }^{1}$, G. Friesen ${ }^{2}$, H.G.Beyer ${ }^{3}$ \\ ${ }^{1}$ Centre for Renewable Energy Systems Technology, Loughborough University, UK; ${ }^{2}$ SUPSI-ISAAC, Cannobio, \\ Switzerland; ${ }^{3}$ Institut fuer Elektrotechnik, Hochschule Magdeburg-Stendal, Germany \\ Corresponding email: m.strobel@,lboro.ac.uk
}

\begin{abstract}
When considering the system yield, one needs to know the uncertainty in key parameters for the annual yield in order to determine the confidence limit. This requires a consideration not only of the instrumentation but also of the operating environment. The importance of this is demonstrated by carrying out an uncertainty analysis for different locations, technologies and instrumentations. The accuracy of the key parameters is determined with regards to whether the uncertainty margins allow meeting contractual obligations for guarantees of results. It is shown that different operating environments have different boundaries. The main uncertainty is in the irradiance which ranges from 0.6$1.5 \%$ and filters into the PR with up to $6 \%$ for northern Europe (Site 1).
\end{abstract}

\section{INTRODUCTION}

The energy yield $\left(\mathrm{Y}_{\mathrm{PV}}\right)$ of $\mathrm{PV}$ modules is the key parameter for assessing the economic viability of installations but it requires being put into the context of long term meteorological datasets. The most crucial performance indicator is thus the performance ratio $\left(\mathrm{PR}^{1}\right)$, which is affected by electrical as well as meteorological uncertainties. These uncertainties add to any deviation from the expected energy production and thus are crucial to be considered. They are commonly quoted as the combined uncertainty or the expanded uncertainty - quantities generally derived via a Type B error analysis [1] from manufacturer data at standard test conditions (STC). This is idealized because at low signal strengths signal-independent offset errors and resolution result in a deterioration of uncertainty. Hence, equal systems will show different uncertainties depending on their measurement environment. Typical achievable uncertainties are investigated for common instrumentations in this paper. The uncertainties are then calculated using information on measurement uncertainties of three systems representing two research systems and a typical system instrumentation. First, the uncertainties of irradiance and maximum power point power $\left(\mathrm{P}_{\mathrm{MPP}}\right)$ are calculated for each data point and then

\footnotetext{
${ }^{1}$ The PR is defined here as the ratio of real measured long term efficiency to STC efficiency.
}

propagated through to the key performance parameters via worst-case scenario error estimation.

\section{THE PV MODEL}

A computer routine for IV curve simulation and MPP extraction was set up using a single diode model with parameters fitted for modules installed at CREST (see [2] for the calculation models used). It was attempted to model two realistic modules by adjusting the number of cells in series and module area without considering interconnection losses. The STC ratings were chosen to be $65.52 \mathrm{Wp}$ for a $6.45 \%$ efficient Module 1 and $185.82 \mathrm{Wp}$ for a $14.87 \%$ efficient Module 2. Furthermore, three sets of environmental data were selected to represent a variety of measurement environments: Site 1 with $750 \mathrm{kWh} / \mathrm{m}^{2}$, Site 2 with 980 $\mathrm{kWh} / \mathrm{m}^{2}$ and Site 3 with $1350 \mathrm{kWh} / \mathrm{m}^{2}$ annual irradiation respectively.

\section{ERROR ANALYSIS}

The three chosen error scenarios are listed in Table 1. Instrumentation 1 and 2 represent two research grade instrumentations and Instrumentation 3 a typical installation. The uncertainties for the first two were calculated from Type B root square sum (RSS) error analyses from manufacturer datasheets in accordance with [1] while the uncertainties for Instrumentation 3 are based on commercially available monitoring systems. From these uncertainties the uncertainties in

- maximum power $\mathrm{P}_{\mathrm{MP}}=\mathrm{I}_{\mathrm{MP}} \cdot \mathrm{V}_{\mathrm{MP}}$

- $\quad$ electrical energy yield: $\mathrm{Y}_{\mathrm{PV}}=\sum\left(\mathrm{P}_{\mathrm{MP}}\right)$

- $\quad$ solar energy yield in plane of array: $\mathrm{Y}_{\mathrm{SOL}}=\sum\left(\mathrm{G}_{\mathrm{POA}}\right)$

- $\quad$ real efficiency $\eta_{\mathrm{rel}}=\mathrm{Y}_{\mathrm{PV}} /\left(\mathrm{Y}_{\mathrm{SOL}} \cdot \mathrm{A}\right)$

- $\quad$ performance ratio $\mathrm{PR}=\eta_{\mathrm{rel}} / \eta_{\mathrm{STC}}$

were calculated for each point of the dataset by simply adding absolute errors for sums and relative errors for fractions producing worst-case estimates independently of correlations [3]. The error of the STC efficiency was assumed to be $2 \%$. The uncertainty analysis in the present work focuses solely on the measurement side, i.e. uncertainties arising from the instrumentation and maximum power point extraction, whereas uncertainties arising from IV modeling were not considered. 


\begin{tabular}{|l|l|l|l|}
\hline Uncertainty & Instrumentation 1 & Instrumentation 2 & Instrumentation 3 \\
\hline $\mathrm{I}_{\mathrm{MP}}$ & $\pm\left(0.2 \% * \mathrm{I}_{\mathrm{MP}}+0.01 \mathrm{~A}\right)$ & $\pm\left(0.7 \% * \mathrm{I}_{\mathrm{MP}}+0.002 \mathrm{~A}\right)$ & $\pm\left(1 \% * \mathrm{I}_{\mathrm{MP}}+0.005 \mathrm{~A}\right)$ \\
\hline $\mathrm{V}_{\mathrm{MP}}$ & $\pm\left(0.1 \% * \mathrm{~V}_{\mathrm{MP}}+0.01 \mathrm{~V}\right)$ & $\pm\left(0.4 \% * \mathrm{~V}_{\mathrm{MP}}+0.00025 \mathrm{~V}\right)$ & $\pm\left(1 \% * \mathrm{~V}_{\mathrm{MP}}+0.02 \mathrm{~V}\right)$ \\
\hline $\mathrm{G}_{\mathrm{POA}}$ & $\pm\left(1.5 \%+2 \mathrm{~W} / \mathrm{m}^{2}\right)$ & $\pm\left(0.7 \%+0.02 \mathrm{~W} / \mathrm{m}^{2}\right)$ & $\pm\left(3 \%+0.3 \mathrm{~W} / \mathrm{m}^{2}\right)$ \\
\hline
\end{tabular}

Table 1 Three error szenarios. The systematic measurement uncertainties are quoted as signal-dependent (\%) and signalindependent (offset) uncertainty.

\section{RESULTS}

The uncertainties of the energy yields vary with location and instrumentation. Figure 1 shows the dependence of the uncertainties of the annual PR for the different sites and instrumentations Module 1. The highest PR uncertainties are to be found for Instrumentation 1 with minima ranging from $0.6 \%$ for PV energy yield uncertainties to $1 \%$ for real efficiency uncertainties up to $3 \%$ for PR uncertainties.

While Instrumentation 3 features up to 10 times higher signal-depend uncertainties the impact on PR uncertainty remains overall lower and less affected by location due to lower offsets. Since $u\left(\mathrm{Y}_{\mathrm{PV}}\right)$ and $\mathrm{u}\left(\mathrm{Y}_{\mathrm{POA}}\right)$ were calculated as the sums of absolute uncertainties for each measurement point of $\mathrm{G}_{\mathrm{POA}}$ and $\mathrm{P}_{\mathrm{MP}}$. an offset component will become more significant where uncertainties would otherwise have been small. Hence, Instrumentation 1 will show the highest uncertainty levels at Site 1 (see Figure 1).

Also, Instrumentation 2 with the lowest measurement offsets is therefore least affected by location - here PR uncertainties range from $2.15 \%$ to $2.25 \%$.

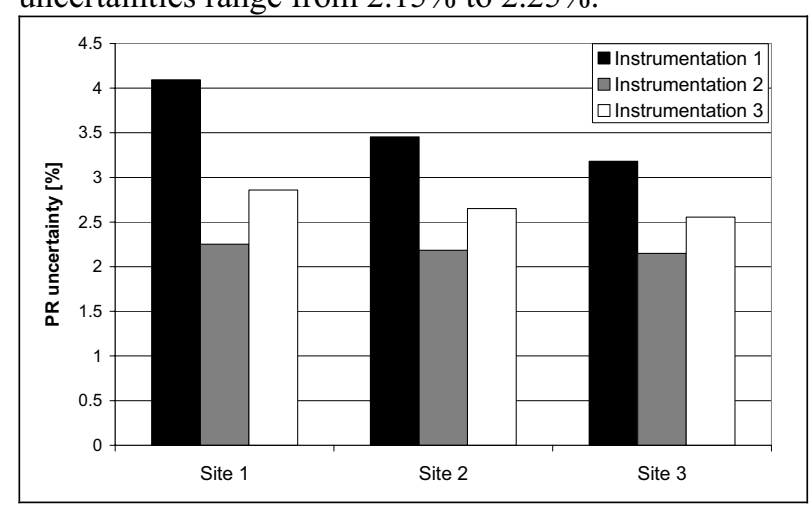

Figure 1 PR uncertainty [\%] for Module 1 depending on instrumentation and site (sites are ordered according to the annual irradiation.

The variation of the PR uncertainty with module rating is illustrated in Figure 2. Generally, Site 1 sees the highest uncertainties with maximum uncertainties of $5.28 \%$ in Jan (Site 1), $4.54 \%$ in Nov (Site 2) and 3.80\% in December (Site 3). These values would be expected for December. Instead the in-plane irradiation measured at Site 2 for November is $6 \%$ lower than for December and on average at $21 \%$ lower levels. This causes higher uncertainties in the energy yields and the PR for that month. The same but to a minor extend holds true for Site 1 in January. The extremely high uncertainties for Site 1 in July are a direct result from very low overall irradiation measurements of that month $(56 \%$ of
August) with low irradiance levels on average (47\% of August).

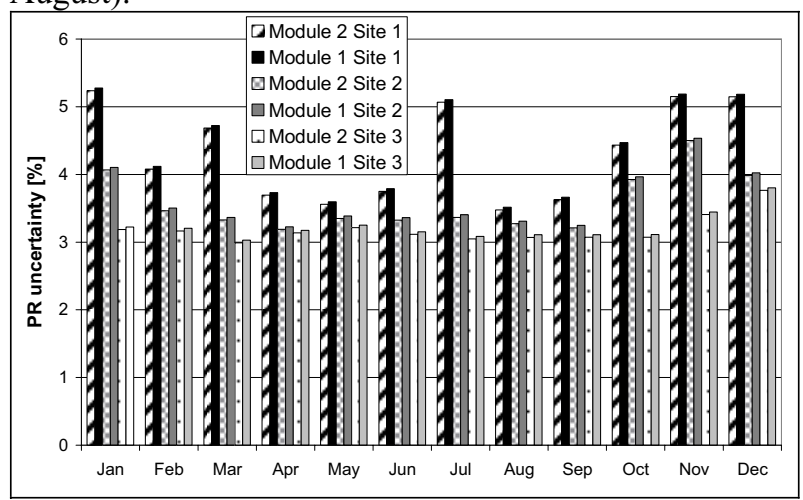

Figure 2 Relative monthly PR uncertainties for

Instrumentation 1 at three sites for both modules.

The overall PR uncertainties are generally smaller for Module 2. However, the difference in $\mathrm{Y}_{\mathrm{PV}}$ uncertainty between the two modules is most apparent at Site 3 throughout the year $(0.0381 \%)$ with an increase during summer time.

\section{CONCLUSIONS}

It could be shown that the influence of measurement uncertainties on the system performance figures are dominated mainly by the measurement offset error component. Typical system instrumentation results in an annual PR uncertainty greater then 3\%. The effect of location is apparent and contributes almost one percent to the PR at Site 1 with Instrumentation 1 for a low efficiency PV module (Module 1). Hence, it is suggested to take great care in reducing systematic errors and to account for systematic offset errors properly when quoting performance indices.

\section{REFERENCES:}

1. Guide to Meteorological Instruments and Methods of Observation. 1996 (Sixth Edition), World Meteorological Organization: Geneva.

2. Gottschalg, R., et al., The influence of the measurement environment on the accuracy of the extraction of the physical parameters of solar cells. Measurement Science and Technology, 1999. 10: p. 796-804.

3. Taylor, J.R., An introduction to error analysis : The study of uncertainties in physical measurements. Second ed. 1997, Sausalito, California, USA: University Science Books. 